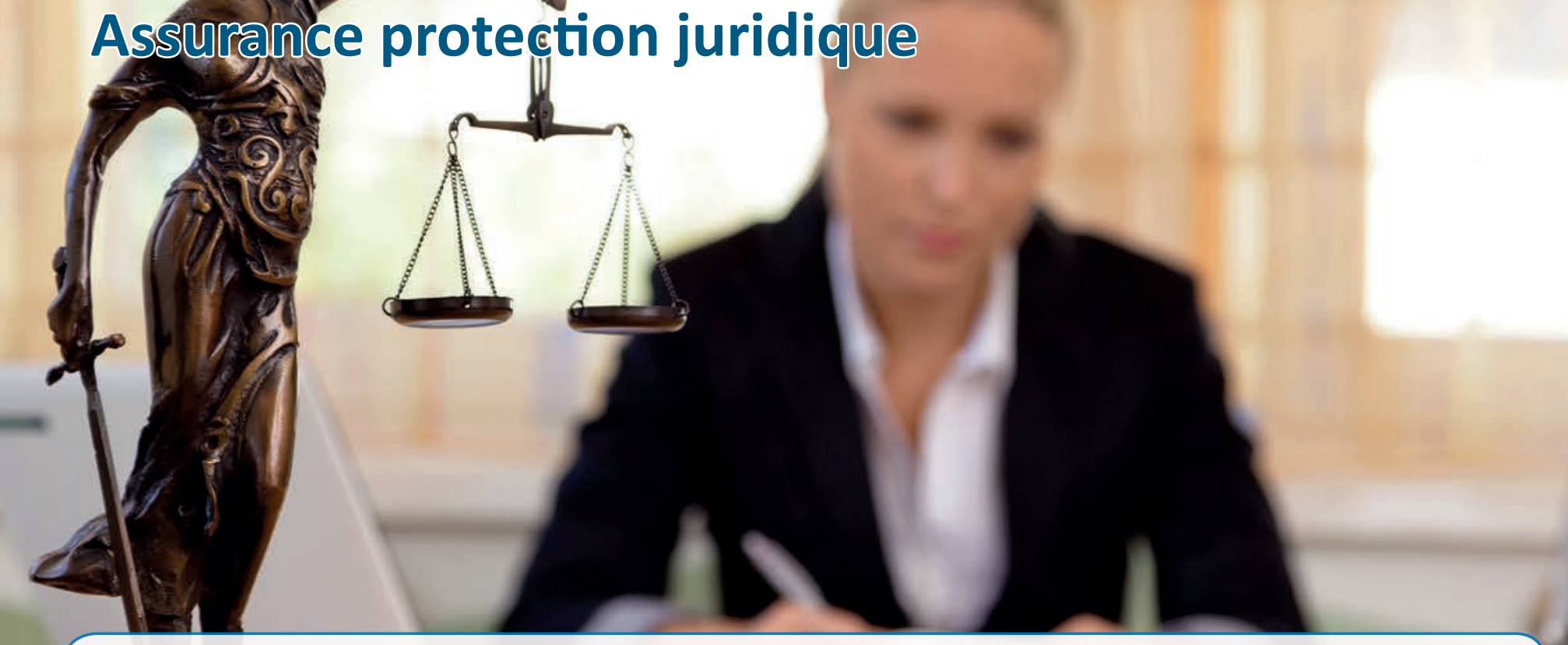

Les risques juridiques liés au domaine de la santé ne sont aucunement comparables à ceux des autres branches. Une solution de protection juridique spécifique au corps médical a été conçue sur la base de ces exigences. Notre solution couvre p.ex. également les litiges en relation avec les audits de rentabilité et la polypragmasie ! Laissez-vous convaincre par notre proposition en commandant une offre au moyen du coupon-réponse ci-dessous.

के

\title{
ASSURANCE PROTECTION JURIDIQUE
}

\section{† FMH SERVICES}

Je souhaite une offre sans engagement ni frais concernant l'assurance protection juridique de FMH Services (Insurance).

Couverture de base pour

$\square$ Fournisseur de prestations salarié

$\square$ Fournisseur de prestations indépendant

$\square$ Cabinet médical de groupe / Personnes juridiques

Personnes suppl. assurées $\quad \square$ Fournisseur de prestations salarié Nombre de personnes Taux d'activité par personne

$\square$ Conjoint comme fournisseur de prestations

$\square$ Employé

$\square$ Indépendant

Veuillez m'envoyer la brochure gratuite «Assurance de protection juridique pour les médecins et le personnel médical».

$\square \quad$ J'ai déjà une assurance protection juridique de FMH Services (Insurance) mais j'aimerais en savoir plus au sujet de la nouvelle couverture complémentaire "Plus " de la protection juridique.

$\square \quad$ Je désire un conseil personnalisé. Merci de me contacter.

Prénom / Nom

Adresse

NPA / Lieu

Tél. privé / prof.

Atteignable de préférence vers

Adresse mail

\section{INSURANCE}

\section{Roth Gygax \& Partner AG}

Moosstrasse 2, 3073 Gümligen

Tel. 0319595000 - Fax 0319595010

mail@fmhinsurance.ch - www.fmhinsurance.ch

Roth Gygax \& Partner AG est une entreprise de conseil indépendante sur le plan juridique et économique recommandée par la société coopérative FMH Services. 